\title{
EFEITO DO ARMAZENAMENTO SOBRE AS PROPRIEDADES TECNOLÓGICAS DA FARINHA, DE VARIEDADES DE TRIGO CULTIVADAS NO BRASIL
}

\section{EFFECT OF STORAGE ON TECHNOLOGICAL PROPERTIES OF WHEAT FLOUR OF BRAZILIAN GROWN WHEATS}

\author{
Mônica R. Pirozi ${ }^{1}$, Rogério Germani ${ }^{2}$ \\ ${ }^{1}$ UFV, Dep. Tecnologia de Alimentos, CEP 36571-000, Viçosa - MG, ${ }^{2}$ CTAA/EMBRAPA, Av. das \\ Américas, 29501, CEP 23020-470, Guaratiba, Rio de Janeiro - RJ.
}

\begin{abstract}
The aim of this work was to evaluate changes in technological properties of newly milled flours of BR-23, BR-35 and Anahuac varieties (Brazilian grown wheat) during storage for 180 days. Quality of samples was analysed for their rheological properties, acidity, falling number, glutomatic test and baking test, after periods of $0,7,15,30,60,90,120,150$ and 180 days. Most evident changes were the increase in flour acitidy and dough elasticity. The other characteristics did not show expressive changes. The flour of Anahuac variety was less influenced by the storage than the other ones. The results showed an increment in the flour quality, during 60-90 days of storage, althoug the baking test did not show expressive changes during all the period of storage.
\end{abstract}

Key words: wheat flour; technological quality; storage; maturation; farinha de trigo; qualidade tecnológica; armazenamento; maturação.

\section{INTRODUÇÃO}

Nos últimos anos a triticultura nacional recebeu uma grande quantidade de novas variedades de trigo, mais adaptadas as condições climáticas e edáficas do país e mais resistentes a pragas e doenças. Tais variedades foram então incluídas em um extenso estudo da avaliação de suas qualidades tecnológicas (GERMANI, 1995), buscando identificar aquelas com maior potencial de mercado. Entretanto, a qualidade da farinha produzida não depende apenas dos fatores relacionados à produção e moagem dos grãos. Um importante agente modificador desta qualidade é o tempo que se passa desde a produção até o consumo da farinha. Este tempo, em que o produto fica armazenado, pode favorecer a sua maturação, alterando com isso as características de determinados componentes de qualidade (POMERANZ, 1978). 
O mecanismo do processo de maturação ainda não é totalmente compreendido, mas é aceito que os grupos tióis (-SH) presentes na proteína do trigo sofrem oxidação, favorecendo a formação de pontes dissulfídicas, que fortalecem o glúten e aumentam a capacidade elástica da massa. Tal oxidação seria promovida pelo oxigênio atmosférico e/ou pela presença de ácidos graxos livres, cuja concentração aumenta na farinha durante o armazenamento (HALTON et al, 1937; CUENDET et alli, 1954; TSEN et al, 1963).

Os resultados obtidos por Cosgrove (1972) demonstram que, após o armazenamento da farinha, houve um aumento na absorção do oxigênio do ar pelas massas formadas. O oxigênio absorvido estaria participando não só das reações de oxidação citadas como também promoveria a oxidação dos compostos carotenóides, deixando a massa mais clara e, consequentemente, melhorando a cor do miolo do pão produzido.

O aumento da acidez da farinha com o armazenamento é também frequentemente relatado pelos pesquisadores, e está provavelmente associado à hidrolise dos lipídeos, que produz ácidos graxos livres (CLAYTON et al, 1972). A presença destes ácidos graxos também favorecem as reações de oxidação na farinha (ARAÚJO et al, 1972).

Pomeranz (1974) cita que, em determinadas condições de armazenamento, há uma tendência ao aumento da acidez, à diminuição da alfa-amilase, ao fortalecimento do glúten e ao aumento do volume do pão. Segundo este autor, o grau de maturação adequado para panificação se estabelece até 1-2 meses de armazenamento, além do qual pode haver um decréscimo do potencial tecnológico, principalmente em farinhas armazenadas sob condições de temperatura e umidade elevadas.

Apesar de ser um tema bastante difundido nos grandes centros produtores de trigo, a alteração da qualidade tecnológica da farinha durante o armazenamento não gerou literatura expressiva no Brasil, e devido a diversidade de variedades, de clima e tipo de solo, há de se esperar resultados diferentes dos encontrados nos demais países. Além disto, a maioria dos trabalhos publicados neste assunto data de meados deste século, época em que os parâmetros considerados eram diferentes dos atuais critérios de qualidade. Neste sentido, o objetivo do presente trabalho foi verificar as alterações dos componentes de qualidade tecnológica da farinha, de três variedades de trigo recém moído, cultivadas comercialmente no Brasil, durante o armazenamento por 180 dias. 


\section{MATERIAL E MÉTODOS}

\section{Matéria-prima:}

Para este trabalho foram selecionadas três variedades de trigo produzidas comercialmente no Brasil, com base em suas classes comerciais (REUNIÃO, 1994): Anahuac (Classe "Superior"), BR-35 (Classe "Intermediária") e BR-23 (Classe "Comum"). Esta classificação (BRASIL, 1994) considera as características tecnológicas da farinha obtida de cada variedade, através de parâmetros de farinografia, alveografia e índice de queda, e determina sua aplicação comercial, conforme apresentdo a seguir:

Classe Melhorador - para misturas com farinha de glúten fraco.

Classe Superior - panificação, produção de massas e pastas alimentícias, produção de crackers.

Classe Intermediária - para uso doméstico e panificação.

Classe Comum - produção de biscoitos, bolachas, pizzas, produtos de confeitaria, rações, massas caseiras frescas, ou para mesclas com trigos das classes melhorador e/ou superior, com fins de panificação ou uso doméstico.

As amostras de grãos de cada variedade, com no máximo 7 dias após a colheita, foram moídas em moinho de laboratório, modelo Quadrumat Senior (Brabender-OHG), após condicionamento a $15 \%$ de umidade e 16 horas de descanso.

\section{Condições de estocagem:}

O material recém moído foi homogeneizado e separado em 18 alíquotas de $1,8 \mathrm{~kg}$ cada, acondicionadas em sacos de polietileno e armazenadas em câmara a aproximadamente $30^{\circ} \mathrm{C}$. Duas amostras de farinha (repetições) de cada variedade foram analisadas após períodos de 0 , $7,15,30,60,90,120,150$ e 180 dias.

\section{Análises:}

Os testes usados na avaliação da qualidade tecnológica foram: acidez alcoólica, segundo o método $\mathrm{N}^{\mathrm{o}}$ 6.1.2.2, do Instituto Adolfo Lutz (1985); umidade e índice de queda, segundo os métodos № 44-15A e 56-01B da AACC (1983), respectivamente; farinografia e 
extensografia em equipamentos Brabender, segundo os métodos №s $54-21$ e 54-10 da AACC (1983), respectivamente; teor e índice de glúten em equipamento Glutomatic, segundo as especificações do fabricante (Perten Instruments); e teste de panificação, pelo método de massa direta (Straigh-dough method), modificada do № 10-10A da AACC (1983), conforme descrito em seguida.

Foram utilizadas duas formulações, apresentadas na Tabela 1. A quantidade de água adicionada foi determinada com base na absorção de água da amostra, obtida na análise de farinografia, decrescida de 2 e 5 pontos percentuais para as formulações Básica e Elaborada, respectivamente. A amilase fúngica foi usada nas massas cujas farinhas apresentaram índice de queda superior a 300 segundos. O tempo ótimo de mistura foi verificado previamente para cada uma das variedades em cada formulação, através do aspecto do "filme" formado pela massa. $\mathrm{O}$ teste foi realizado em padaria experimental da National MGF Co., seguindo as etapas apresentadas na Figura 1.

Tabela I - Formulações usadas no teste de panificação:

\begin{tabular}{|lcc|}
\hline & \multicolumn{2}{c|}{ Formulação } \\
\cline { 2 - 3 } Ingredientes & Básica & Elaborada \\
\hline Farinha de trigo & $100 \mathrm{~g}$ & $100 \mathrm{~g}$ \\
Fermento fresco prensado & $5 \mathrm{~g}$ & $5 \mathrm{~g}$ \\
NaCl comercial & $2 \mathrm{~g}$ & $2 \mathrm{~g}$ \\
Ácido ascórbico & $60 \mathrm{ppm}$ & $60 \mathrm{ppm}$ \\
Amilase fúngica (se necessária) & $0,028 \mathrm{~g}$ & $0,028 \mathrm{~g}$ \\
Açúcar & - & $5 \mathrm{~g}$ \\
Gordura vegetal hidrogenada & - & $3 \mathrm{~g}$ \\
Água & variável & variável \\
\hline
\end{tabular}

A avaliação dos pães foi feita seguindo um critério de notas, atribuídas de 1 a 10 para quatro diferentes quesitos (aparência e cor da crosta, espessura da crosta, granulação e cor do miolo), podendo cada amostra somar até 40 pontos no escore total. Também foi feita avaliação do volume específico dos pães, segundo Germani (1986). 


\section{Delineamento experimental:}

O ensaio seguiu o Delineamento Inteiramente Casualizado, em estrutura fatorial 3x9, com duas repetições, sendo os tratamentos as três variedades de trigo e os nove períodos de armazenamento. A análise estatística foi realizada no programa SANEST, e seguiu as recomendações de Pimentel Gomes (1982), Aquino (1984) e Campos (1991).

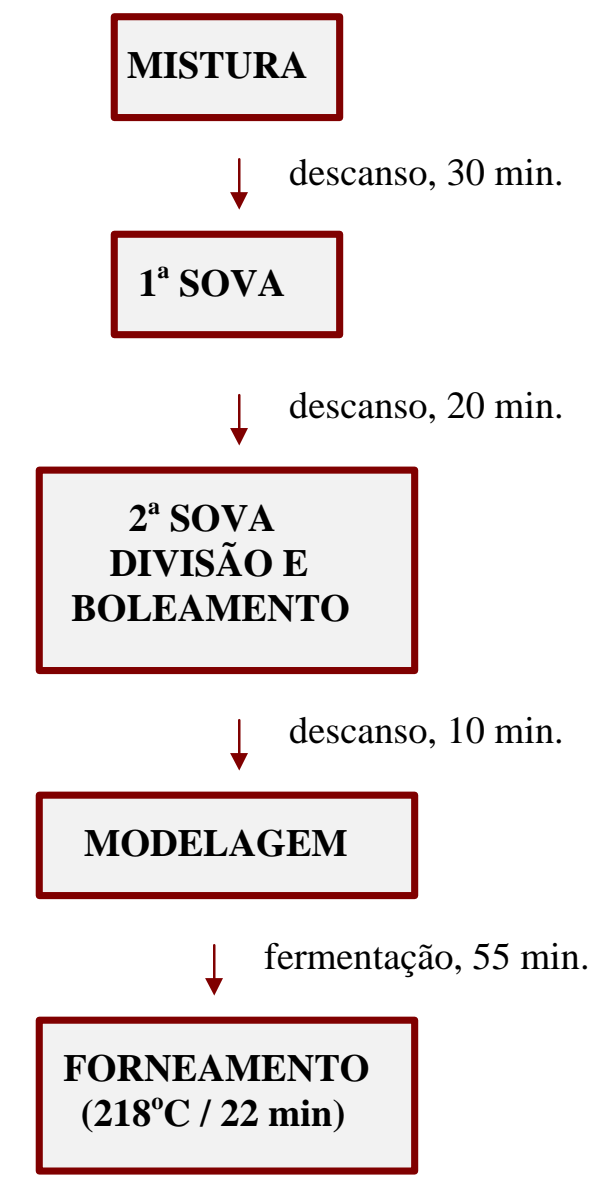

Figura 1 - Fluxograma do teste de panificação experimental.

\section{RESULTADOS E DISCUSSÃO}

O armazenamento da farinha de trigo promoveu alterações estatísticamente significativas, apesar de pouco expressivas, em quase todas as características avaliadas. 
Segundo Aquino (1995), o número de níveis do tratamento "tempo de armazenamento" garante a significância das alterações observadas, contudo, em muitos casos, esta variação não seguiu um modelo definido, de forma que as curvas de regressão não se ajustam adequadamente $\left(\mathrm{r}^{2}\right.$ é baixo até o modelo quadrático).

O teor de umidade (Figura 2) decresceu ligeiramente durante o armazenamento, o quê era esperado, devido as condições mantidas na câmara de armazenamento. Houve um aumento no índice de queda (IQ) durante o experimento, e este aumento foi bem distinto entre as três variedades, sendo maior para Anahuac e menor para BR-23 (Teste de Tukey, ao nível de 5\% de probabilidade), durante todo o período de estudo (Figura 3).

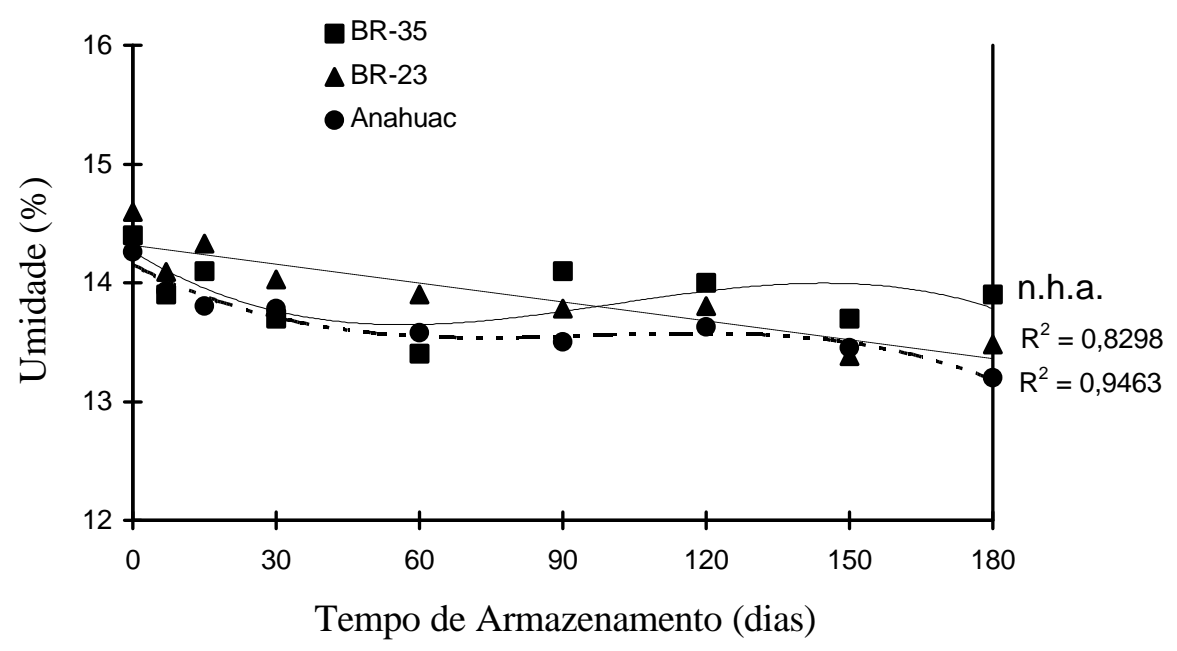

Figura 2 - Variação do teor de umidade nas farinhas, durante o armazenamento. (n.h.a. - não houve ajuste para equação de regressão). 


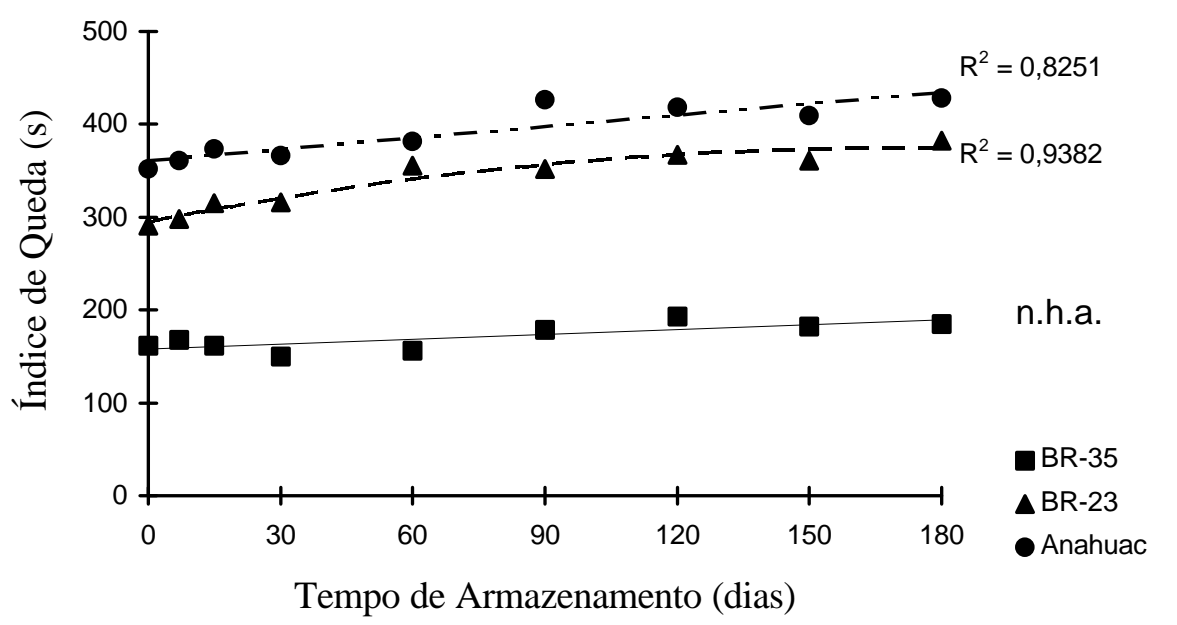

Figura 3 - Variação do ìndice de Queda (s) das farinhas, durante o armazenamento. (n.h.a. - não houve ajuste para equação de regressão).

Sreenivasan (citado por POMERANZ, 1978), verificou semelhante comportamento para o IQ, em trabalho com arroz. Halton e Fisher (1937) sugerem que, durante o armazenamento, pode ocorrer tanto uma perda da atividade enzimática pelo material, quanto uma maior resistência, principalmente do amido, ao ataque enzimático.

Para acidez alcoólica, não houve diferença significativa entre as variedades no início do experimento, mas foi observado um desenvolvimento distinto, maior para a BR-35 e menor para Anahuac (Teste de Tukey, ao nível de 5\% de probabilidade), após os 180 dias de estocagem (Figura 4). Segundo Pomeranz (1974), a hidrólise de proteína e carboidratos na farinha armazenada é mais lenta em relação à que ocorre nos lipídeos, o que indica que o incremento verificado na acidez pode ser reflexo do aumento da concentração de ácidos graxos livres. Apesar de significativos, os valores observados ao final do experimento mantiveram-se, em todas as variedades, abaixo do limite máximo de $2,0 \mathrm{ml}$ de sol. $\mathrm{N} \% \mathrm{v} / \mathrm{p}$, estabelecido pelo Ministério da Saúde (BRASIL, 1991).

As características farinográficas avaliadas neste trabalho mostraram pequena alteração. Houve um aumento médio de 0,85 pontos percentuais na absorção de água das farinhas, o que pode estar refletindo uma modificação na dispersibilidade do glúten. As demais características 


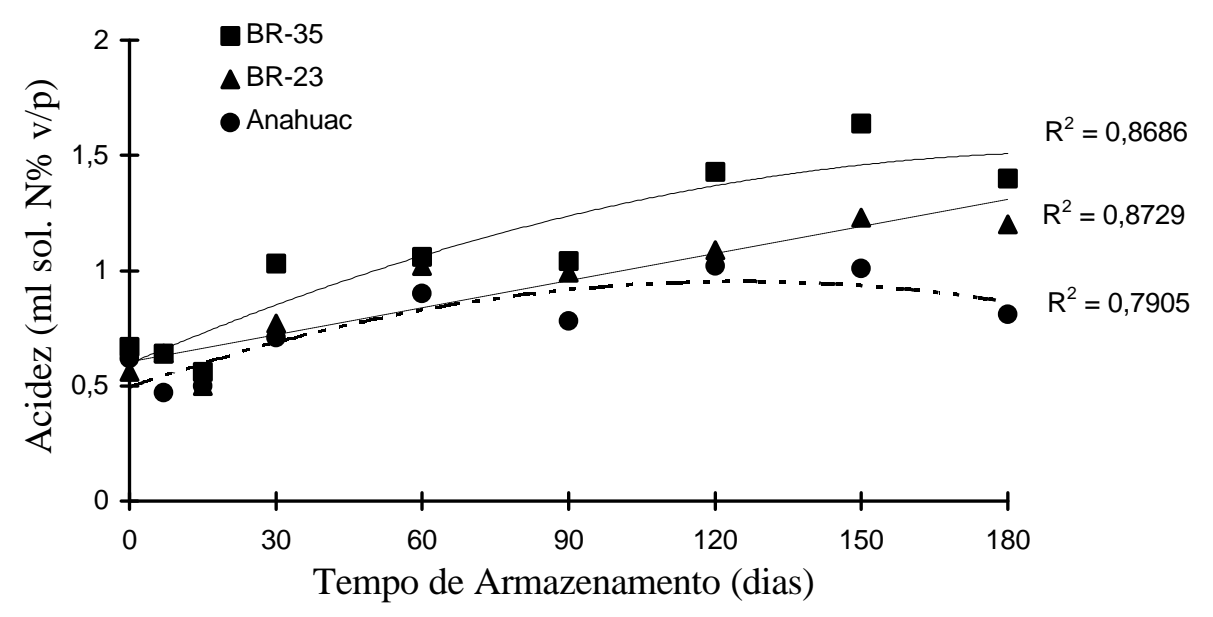

Figura 4 - Variação da Acidez Alcoólica ( $\mathrm{ml}$ sol. N\% p/v) das farinhas, durante o armazenamento.

(tempo de desenvolvimento da massa, estabilidade e valor valorimétrico) não mostraram alterações para quaisquer das variedades estudadas. Apesar disto, os farinogramas apresentam alterações visíveis (Figura 5), como o espessamento da (largura da) faixa e o arredondamento do formato da curva, no ponto de máxima consistência, que podem estar indicando um aumento relativo na força da farinha. Estas alterações foram mais nítidas nas variedades BR-35 e BR-23.

Os parâmetros de extensografia mostraram as mais nítidas alterações com o armazenamento (Figura 6), sempre no sentido da diminuição da extensibilidade e aumento da elasticidade, número proporcional e área da curva. A variedade Anahuac apresentou as melhores características até 90 dias de armazenamento, após o qual, as massas que inicialmente se apresentaram macias tornaram-se ressecadas e endurecidas, principalmente com 180 dias de armazenamento, e com 90 e 135 minutos de descanso (tempo de relaxamento). As massas formadas com as variedades BR-23 e BR-35, entretanto, apresentaram-se moles e pegajosas no início do experimento, e se tornaram mais firmes e macias a partir de 90 dias de armazenamento, apesar de não atingirem a consistência ótima mesmo ao final do trabalho. Resultados semelhantes foram observados por Cuendet et al. (1954), que atribuíram tais alterações às reações oxidativas das proteínas e lipídeos da farinha de trigo, fortalecendo consideravelmente o glúten. 


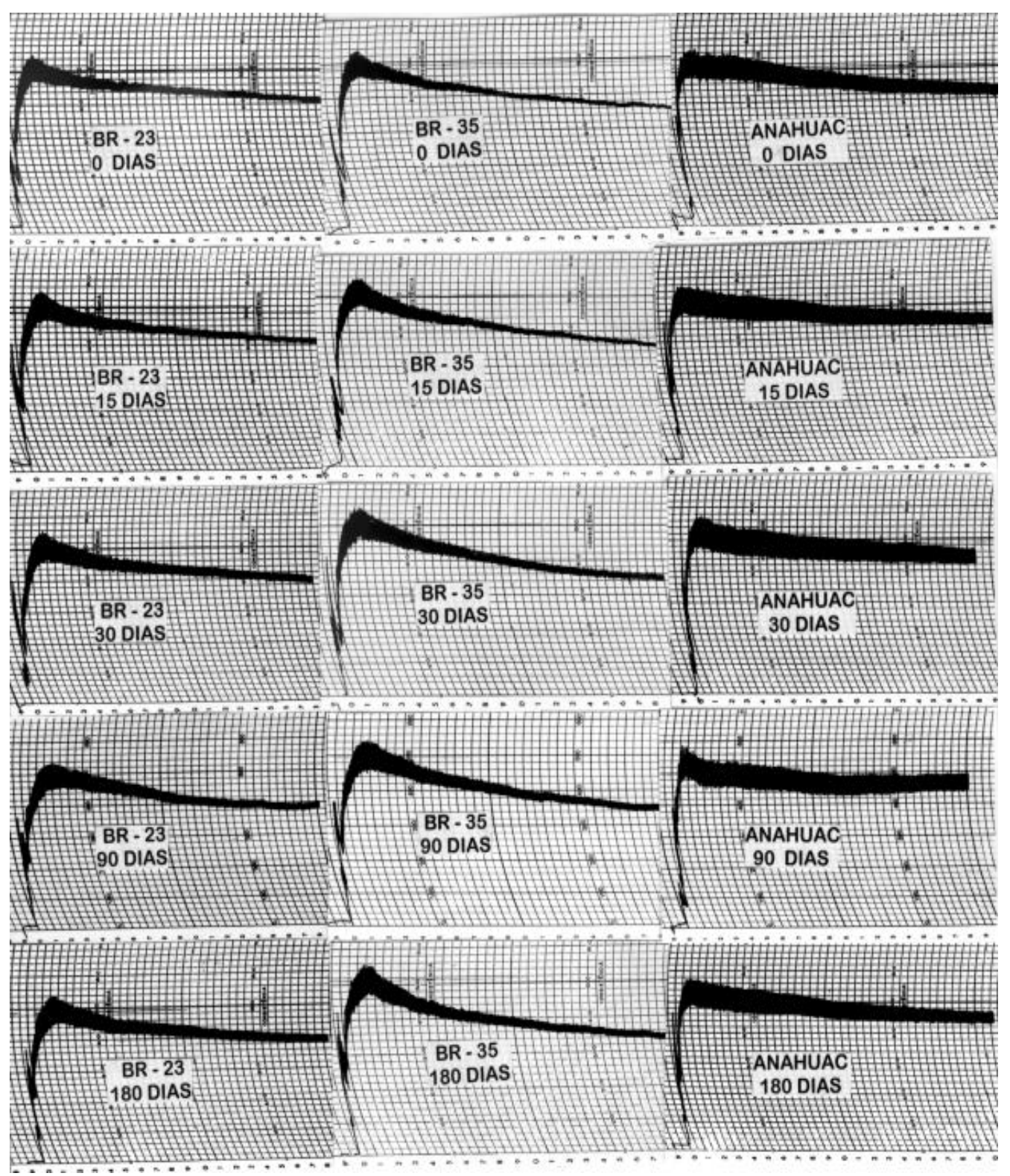

Figura 5 - Variação das características farinográficas durante o armazenamento. 

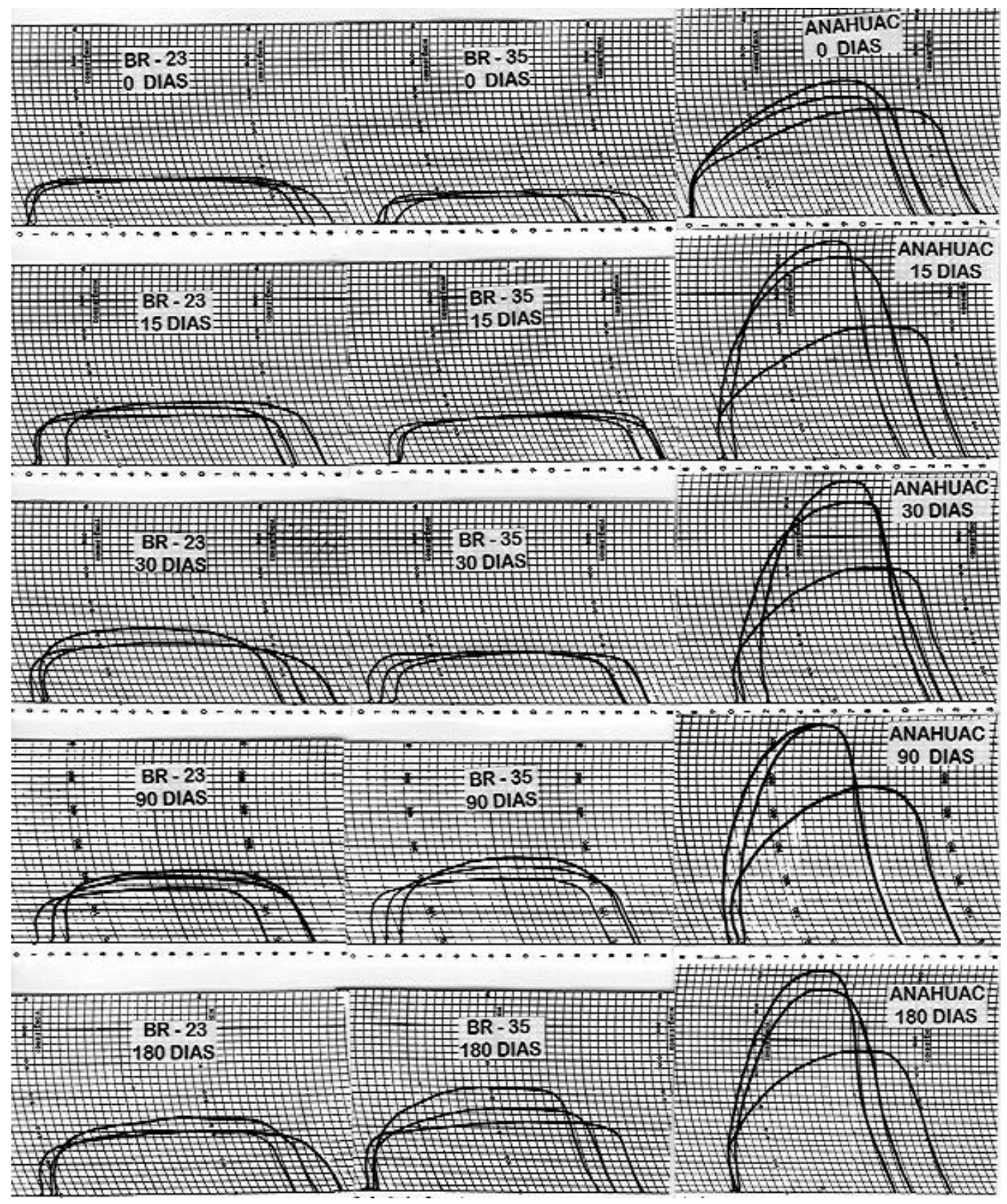

Figura 6 - Variação das características extensográficas durante o armazenamento.

A análise do teor e índice de glúten na variedade Anahuac não mostrou qualquer alteração durante todo o armazenamento (ao nível de 5\% de significância), tendo sido 
verificado o menor teor e o maior índice de glúten que as demais variedades (significativo pelo Teste de Tukey, ao nível de $1 \%$ de probabilidade). Para BR-23 e BR-35, houve uma certa estabilidade até 30 dias, seguido de decréscimo acentuado tanto do teor como do índice de glúten (Figura 7).
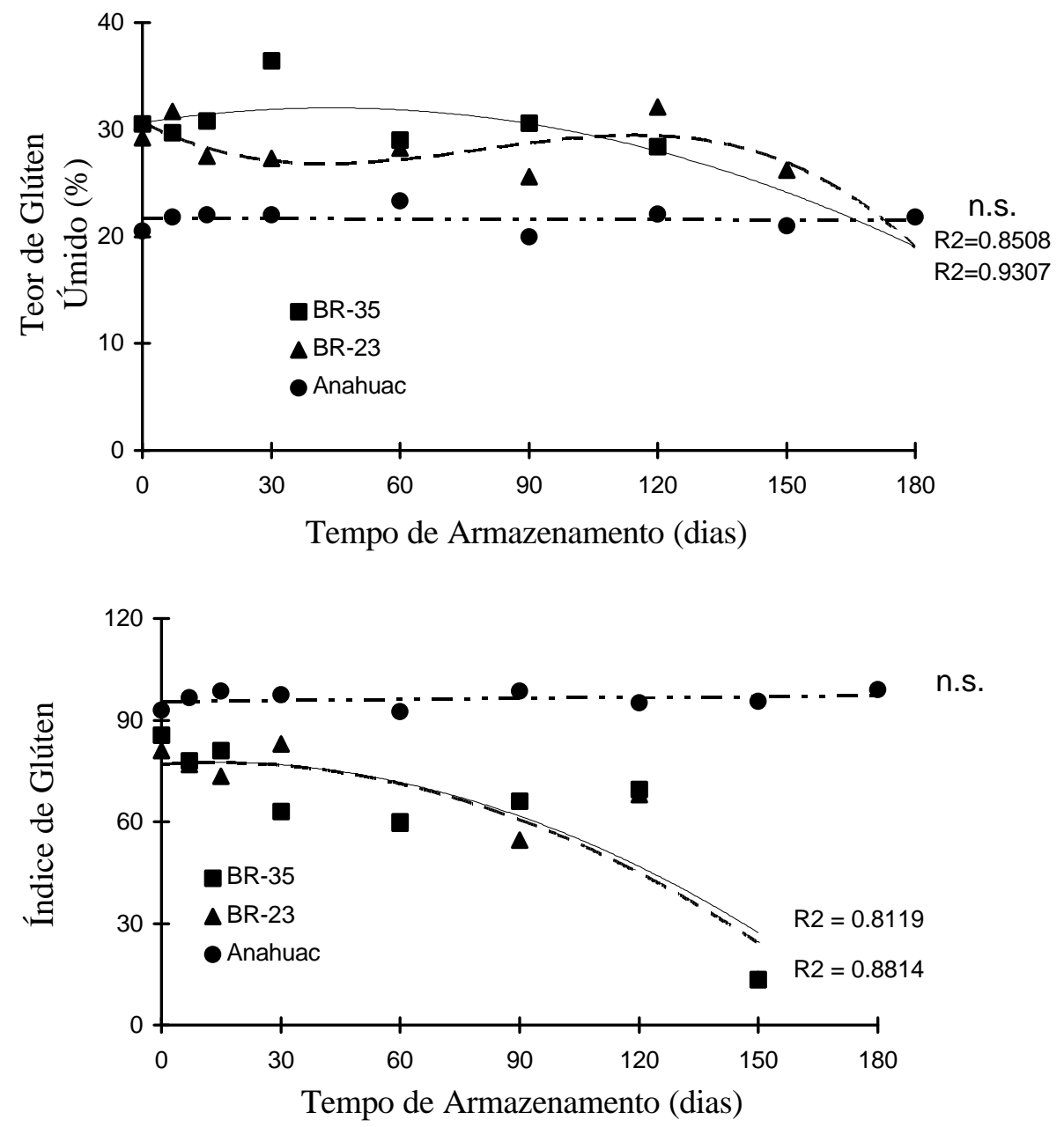

Figura 7 - Variação do Teor e Índice de Glúten das farinhas, durante o armazenamento.

Na prática, o teste com o Glutomatic pareceu ineficiente para amostras de farinha fraca, nas condições deste experimento, pois após 120 e 150 dias de armazenamento não foi possível 
extrair glúten das farinhas das variedades BR-35 e BR-23, respectivamente, já que este apresentava (em ambas amostras) um aspecto desuniforme, desagregado e com grande quantidade de amido que não foi retirado com a operação padrão de lavagem do equipamento, o quê tornou impossível qualquer avaliação.

O teste de panificação não demonstrou alterações significativas (ao nível de 5\% de probabilidade) para o escore total (barras) ou volume específico dos pães (linhas), com o tempo de armazenamento, apesar de apresentar, para formulação elaborada, uma leve tendência a diminuição do volume específico (Figura 8). A variedade Anahuac produziu pães de menor volume em ambas formulações, e de menor escore total com a formulação Básica (teste de Tukey, ao nível de 5\% de probabilidade), o quê deve ser reflexo do seu baixo teor de proteína, em torno de 9,5\%. Zeleny (1978) afirma que a farinha de trigo adequada a panificação deve conter pelo menos $11 \%$ de proteína. Os ingredientes usados na formulação Elaborada melhoraram sobremaneira as massas, de modo que não houve distinção significativa do escore total entre as variedades testadas.

Apesar de não refletir nas características do pão produzido, o tempo de armazenamento propiciou massas mais macias para as variedades BR-35 e BR-23, o que, de certa forma, pode contribuir para aumentar a eficiência do processo de panificação.

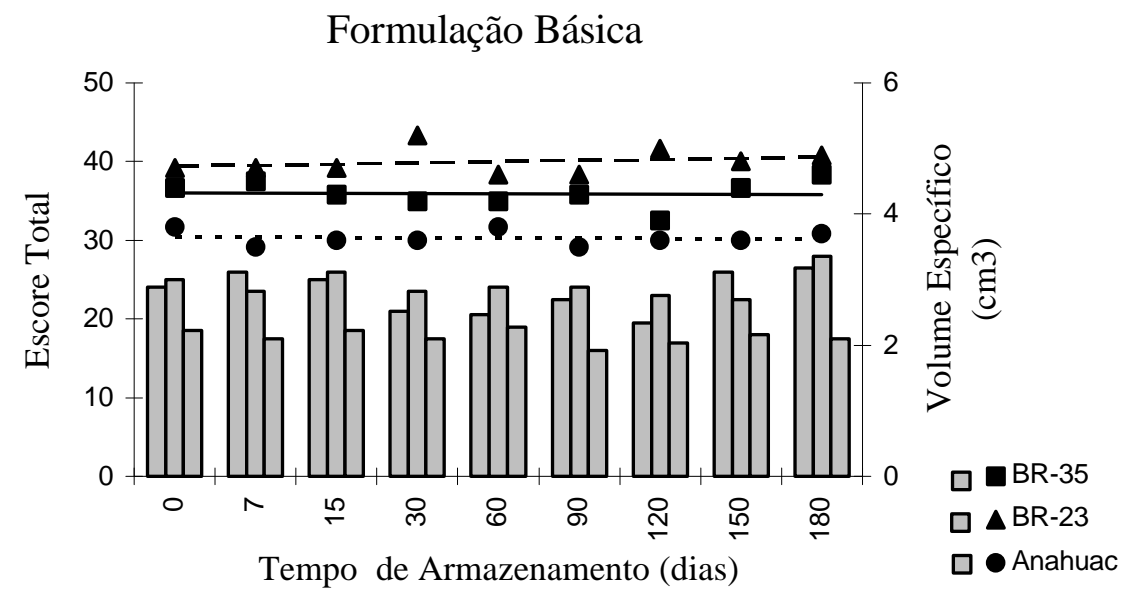




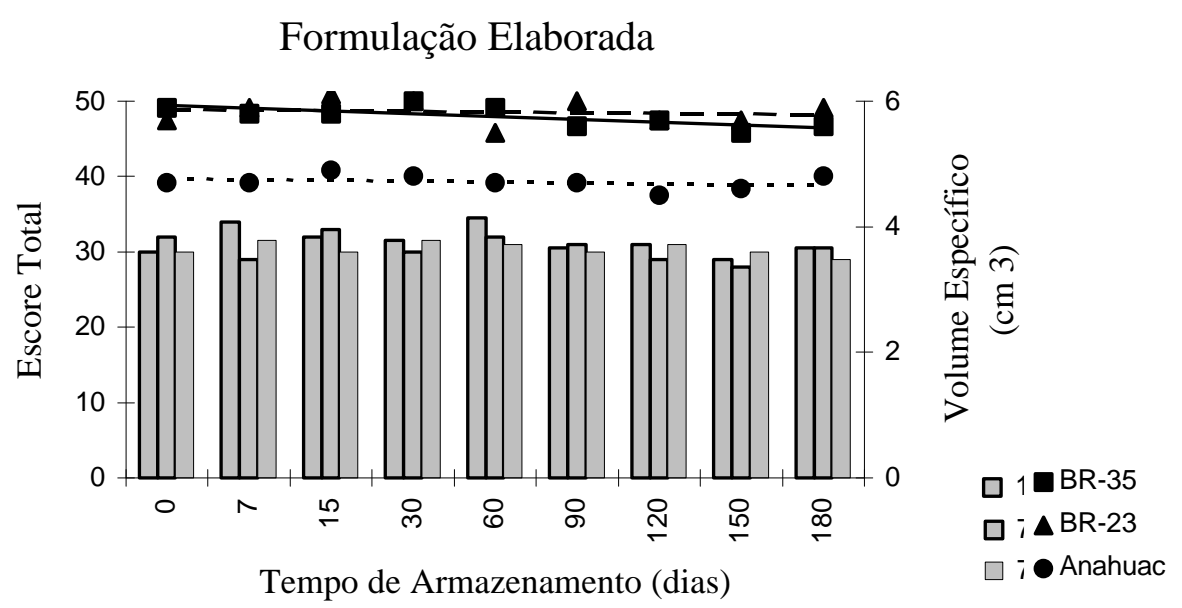

Figura 8 - Variação do Escore Total (barras) e Volume Específico (linhas) dos pães.

\section{CONCLUSÃO}

O tempo de armazenamento produziu algumas alterações expressivas, principalmente o aumento da acidez da farinha e da elasticidade da massa. Os testes de farinografia e de panificação não apresentaram modificações relevantes. Nas variedades BR-23 e BR-35, os testes de teor e índice de glúten mostraram clara tendência a um decréscimo na qualidade, enquanto na Anahuac não houve alteração nestes parâmetros.

$\mathrm{Na}$ maioria dos testes realizados, as variedades da Classe "Comum" (BR-23) e "Intermediário" (BR-35) mostraram alterações mais expressivas dos seus componentes de qualidade do que a da Classe "Superior" (Anahuac). 
De modo geral, a pequena alteração promovida nos parâmetros de qualidade da farinha pode ser devida a pouca exposição ao oxigênio do ar, uma vez que as amostras foram acondicionadas em embalagens plásticas. Ainda que na panificação não se tenha observado alteração significativa, pode-se concluir que a qualidade tecnológica da farinha apresentou melhora até 60-90 dias de armazenamento. As alterações subsequentes foram dependentes da variedade da amostra utilizada.

\section{REFERÊNCIAS BIBLIOGRÁFICAS}

AMERICAN ASSOCIATION OF CEREAL CHEMISTS. Approved methods of... 7.ed.rev. St. Paul: AACC, 1983. v.1,2.

AQUINO, L.H.de. Estatística experimental. Lavras: ESAL, 1991. 252p.

AQUINO, L.H.de. Informação pessoal. Lavras: UFLA, 1995.

ARAÚJO, W.M.C. e CIACCO, C.F. Revisão: funcionalidade dos lipídeos da farinha de trigo na panificação. Rev. Ciênc. e Tecnol. Alimentos. São Paulo, v.12, n.1, p.3-13. jan./jun., 1992.

BRASIL. Ministério da Saúde. Compêndio nacional de normas e padrões para alimentos. Brasília, 1991. (Resolução $n^{0}$ 12/78).

BRASIL. Ministério da Agricultura, do Abastecimento e da Reforma Agrária. Norma de identidade, qualidade, embalagem e apresentação do trigo, para comercialização interna. Brasília, 1994. (anexo da portaria $\mathrm{n}^{0}$ 167, de 29 de julho de 1994).

CAMPOS, H. de. Estatística básica aplicada a experimentação com cana-de-açúcar. 4.ed. São Paulo: Fundação de Estudos Agrários Luiz de Queiroz, 1984. 287p.

CLAYTON, T.A.; MORRISON, W.R. Changes in flour lipids during storage of wheat flour. J. Sci. Food Agric. London, v. 23, n.7, p. 721-723, Jul., 1972.

COSGROVE, D.J. The absortion of oxygen from air by flour batters: changes in the rate of uptake due to ageing of the flour. J. Sci. Food Agric., London, v.7, n.10, p.668-672, Oct., 1972. 
CUENDET, L.S.; LARSON, E.; NORRIS, C.G.; GEDDES, W.F. The influence of moisture content and other factors on the stability of wheat flours at $37,8^{\circ} \mathrm{C}$. Cereal Chem., St. Paul, v.31, n.5, p.362-389, Sep./Oct., 1954.

GERMANI, R. Comparison of some physical and biochemical characteristics of hard red spring and hard red winter wheat. Fargo: NDSU, 1986. 154p. (PhD Thesis)

GERMANI, R. Adequação tecnológica do trigo brasileiro às necessidades da agroindústria e do consumidor. Relatório de Projeto. Sistema EMBRAPA de Planejamento. Comissão Técnica do Programa X. Rio de Janeiro:EMBRAPA/CTAA, 1995.

HALTON, P.; FISHER, E.A. Storage of wheaten flour II: the absortion of oxygen by flour when stored under various conditions. Cereal Chem., St. Paul, v.14, n.3, p.267-291, May/Jun., 1937.

INSTITUTO ADOLFO LUTZ. Normas analíticas do ... II: métodos físicos e químicos para análise de alimentos. São Paulo: IAL, 1985.

PIMENTEL GOMES, F. Curso de estatística experimental. 10 ed. São Paulo: Nobel, 1982. 430p.

PIXTON, S.W.; HILL, S.T. Long-term storage of wheat II. J. Sci. Food Agric. London, v.18, n.3, p.94-98, Mar., 1967.

POMERANZ, Y. Biochemical, functional and nutritive changes during storage. In: CHRISTENSEN, C.M. Storage of cereal grains and their products. 2 ed., c.2, p.56114. St. Paul: AACC, 1974.

POMERANZ, Y. Wheat: chemistry and technology. 3 ed. St. Paul: AACC, 1978. 821p.

TSEN, C.C.; HLYNKA, I.I. Flour lipids and oxidation of sulfhydryl groups in dough. Cereal Chem., St. Paul, v.40, n.2, p.145, Mar./Apr., 1963.

ZELENY, L. Criteria of wheat quality. In: POMERANZ, Y. Wheat: chemistry and technology. 3ed., p.19-45. St. Paul: AACC, 1978.

Received: 01 August 1997; Revised: 02 September 1997; Accepted: June 1998. 